\title{
Personalized contents based on cognitive level of student's computational thinking for learning basic competencies of programming using an environment b-learning
}

\author{
Arturo Rojas López \\ Division of TIC \\ Universidad Tecnológica de Puebla \\ Antiguo camino a la resurrección 1002-A \\ (+52) 2223088861 \\ arturo.rojas@utpuebla.edu.mx
}

\author{
Francisco J. García-Peñalvo \\ GRIAL Research Group, \\ Research Institute for Educational Sciences, \\ University of Salamanca \\ Paseo de Canalejas, 169 \\ 37008 Salamanca, Spain \\ +34923294500 3433 \\ fgarcia@usal.es
}

\begin{abstract}
The main objective of the research is to determine the efficiency of using an environment b-learning in the acquisition of basic skills of programming though customizing the content for each student, to achieve a set of activities that can be used will be designed in the Moodle platform and contribute to teaching an initial programming course, considering three skill levels (basic, intermediate and advanced) of computational thinking of students. A mixed methodology approach will be implemented to achieve the objectives. The quantitative approach, whose characteristics using statistical measure phenomena, experimentation and use cause-effect analysis allow a sequential, deductive and testing process in generating results. The qualitative approach is conducted basically in natural environments and meanings are extracted from data allow a process that context the phenomenon and depth of ideas. To measure the cognitive level of students in computational thinking, instruments will be designed based on the bank of items released by the Computer Olympiad Talent Search in order to have reliable instruments (international proposal), valid (measures learning) and objectives (it focuses on the concept to measure) that they match with contents of subject. The main result is to generate personalized education, a learning experience that contributes to student motivation in tune with the academic goals of initial programming courses.
\end{abstract}

\section{CCS Concepts}

- Social and professional topics Computational thinking - Applied computing Education

\section{Keywords}

Computational Thinking; Computer/Programming Course; Curriculum Design; Educational Programming; Engineering Course; Engineering Education; Higher Education; Learning Programming; Programming; Programming Teaching; Students; Teaching; Work in Progress.

\section{CONTEXT AND MOTIVATION THAT DRIVES THE DISSERTATION RESEARCH}

The teacher is the key piece of functionality and efficiency of a university educational model for selecting under his experience and creativity a learning environment, he allows achieve specific objectives. Computer programming is an activity that creates software technology; however, there are careers that only bet on the model of learning in classroom.

In the material of subject matters is generally indicated what is to be taught and orientation of the strategy to achieve the objectives, i.e., indicated the course content, methods and techniques, as well as the means and teaching materials, but make no mention of technologies or support of a technological medium, being in the network are good choices of material for learning a programming language, such as Codecademy, Learnjava and AIDE. Internet may well provide information to students about the contents of the class, offer codes programs and videos that illustrate the development with new technologies, but there is the problem of the acquisition of basic skills to learn computer programming and development software in general; the main reason "from the point of view of the student is not to have the right mental abilities to solve problems" [1], considering the concept of Computational Thinking (CT) popularized by Jeannette M. Wing [2] and recently introduced by Google for Education, the student lacks a set of skills and techniques to "the process of solving a problem, such as logical ordering, data analysis and creating solutions using a series of orderly steps, it is therefore essential for the development of computer applications"[3]. The work to be performed will offer an educational innovation from content design, personalized educational service and measurement of computational thinking of students to avoid "repeated courses of past experiences and exemplify a transfer of knowledge through assessing the effectiveness of learning and student motivation with active participation of institutional resources" [4].

\section{STATE OF THE ART}

The term computational thinking was made popular by Jeannette M. Wing, with her definition "computational thinking involves solving problems, designing systems, and understanding human behaviour, by drawing on the concepts fundamental to computer science" [2]. Wing revisited the topic and provided this new definition "Computational thinking is the thought processes involved in formulating 
problems and their solutions so that the solutions are represented in a form that can be effectively carried out by an information-processing agent" [5]. García defined computational thinking as "the application of high level of abstraction and an algorithmic approach to solve any kind of problems" [6]. Interest in teaching the Computational Thinking at an early age is presented through the document Standards in Computer Science [7] at North America, project and website TACCLE3 from Spain [8] with work in progress [9], [10] and Computing our future [11], and its impact is important that James and George [12] considers a root element for the success of the student in Computer Science. To teach programming methodology, it would be useful to know the cognitive level of student in Computational Thinking through an assessment, as the work presented by Roman Perez and Jimenez who designed a Test of computational thinking and displayed for "measures pre-test of initial level and early detection of students with high aptitude for computer programming tasks" [13].

Personalized education [14] [15] [16] [17] [18] [19] and its relationship with ICT provides an approach to "help every human being to establish and maintain valuable links with reality" [20] and Gao say that "it will take the place of the standard education" [21], a recent example is the work of Tekin, adapting teaching methodologies, particularly the sequence the material is presented to the student in order to improve the final grade for the course digital signal processing [22]. Moodle is a popular and very good tool in the academic environment that serves as assistant in academic communication between teacher and student use in 224 countries and 69375 registered sites confirm [23]. Moodle allows blended learning model, as described by Garcia [24], with results reported in the context of higher education [25], [26]. The development of activities in the Moodle platform contribute to student academic growth, understanding that each is unique as a person and learn mode and different rhythms and to achieve it can be tailored experiences contributions such as SeinEchaluce, Fidalgo and García inverse applying methodology supported teaching b-learning to "bring home the lesson and homework to the class" [27] in the course of programming.

\section{HYPOTHESIS STATEMENT}

The research work is guided by the following question.

What basic programming skills obtained by students studying an initial course of programming methodology by participating in a blearning model that provides personalized content based on their cognitive level of computational thinking?

The hypothesis for the above question is:

The participation of students in a b-learning environment designed based on their uniqueness of learning and personalization content from the cognitive level of computational thinking, contributes to the acquisition of basic skills programming.

\section{RESEARCH OBJETIVES}

General objectives:

- Determine the efficiency of using an environment b-learning in the acquisition of basic skills of programming customizing the content for each student.

- Design a set of activities, considering three skill levels (basic, intermediate and advanced) of computational thinking of students, which can be used in the Moodle platform and contribute to teaching an initial programming course.

Specific objectives:

- Assess the current contents of the Moodle platform used in the course of programming methodology taking as a case study ICT division at the Technological University of Puebla.

- Review the status of art through a systematic review of the literature on the use of b-learning environments in teaching programming and customization of content considering the uniqueness of the students on their knowledge of computational thinking.

- Determine the parameters for measuring the efficiency of activities designed for teaching programming methodology and future proposals.

\section{APPROACH AND METHODS}

The research methodology provides a way to carry out scientific research as well as "activities that the investigator must make to develop a study for the purpose of producing knowledge and theories or solve practical problems" [28]. Scientific research is conceived as a set of systematic and empirical processes applied to the study of a phenomenon; it is dynamic, changing and evolving, it manifests itself in three ways: quantitative, qualitative and mixed. The project to be developed will generate new knowledge by offering a comprehensive solution in the acquisition of basic skills programming to students who study a degree in engineering or any variations called in relation to software development; in addition to addressing two basic questions: "how fast is it possible to teach students to learn more effectively and how is possible to teach all students that learn at higher power" [29].

A mixed approach is that will be implemented to achieve the objectives. The quantitative approach whose characteristics using statistical measure phenomena, experimentation and use cause-effect analysis allow a sequential, deductive and testing process in generating results. The qualitative approach is conducted basically in natural environments and meanings are extracted from data allow a process that context the phenomenon and depth of ideas.

Considering the case study, the population includes all new students who study the subject Programming Methodology in the period from September to December 2016, the allocation of students and teachers is determined by the director ICT division, at least two groups representing experimental groups will be chosen and those who work with the classroom method represent control groups. The experimental groups will be used to initially know the number of students who have clear definition of Information Technology, that is, if they know the career they are studying, measure the skills of computational thinking and to determine the content of your personalized learning. Although generally the research is done on a sample of the population by saving time and resources, it is possible that in the 
experimental and control groups can apply the respective instruments, still we have a sample no probabilistic or targeted because of characteristics of research, as students choosing not depend on the probability, and be exploratory in qualitative approach to document blearning experience of students.

To measure the cognitive level of students in computational thinking, we will design a test based on "the bank of items released by the Computer Olympiad Talent Search" [13] in order to have reliable instruments (international proposal), valid (measures learning) and goals (focus is on the concept to measure) that match with the contents of the subject.

\section{RESULTS}

We have a justified proposal to use the evaluation of Computational Thinking and determine how to study the course of programming methodology for new students. The Selby's study [30] explores the relationship between the CT, teach programming and Bloom's taxonomy; initially developed a definition of CT skills including generalization, decomposition, abstraction, algorithmic design and evaluation; subsequently mapped to the cognitive domain of Bloom's taxonomy to concentrate as follows: at the Application level skill Generalization, Analysis skills of Abstraction and Decomposition, Synthesis ability of algorithmic design and Evaluation corresponds to the ability evaluation.

The definition of the relationship that we have between knowledge of the course Programming Methodology and the CT is as follows:

- The thematic unit One: "basics" in the concept Knowledge indicates in his six verbs issues of level two of Bloom's taxonomy (Identify, recognize and describe), in the concept Know to Do a verb at the same level and other in fourth (Sketch) so they are in the Know level and Analyze level therefore correspond to the skills of Abstraction and Decomposition.

- The thematic unit Two: "expressions" used in the three subjects the verb Identify in concept Knowledge that corresponds to level two of Bloom, while in the concept Know to Do uses twice verbs of level three Apply corresponding to the Generalization ability.

- The thematic unit Three: "algorithms and flowcharts" has four themes, the concept Knowledge displayed verbs of cognitive level two Understanding and the concept Know to Do a verb level five Evaluate, besides indicating programming exercises using the paradigm structured programming, so corresponds to the skills Evaluation and Algorithmic design.

Therefore, using the mentioned relationship and the manner in which are determined the contents of the subject, the reagents are chosen to evaluate the CT of new students and provide an initial learning environment where motivated to study the subject with based on the identified skills.

The reagents were chosen from two recognized sources at International level: the contest "about informatics and computational fluency school age" [13] UK Bebras [31] and Computer Olympiad Talent Search [32] "that aims to guide South African students with more skills in CT towards technical careers"; because its original form is in English, a Spanish translation is done. The Bebras exercise called Mobile assesses greatly the ability of decomposition, the ratio of the image with the expression of numbers and parentheses leads to determine that the mobile is a small mobile composition see Figure 1.

The exercise named Kangaroo, also Bebras, noted for its assessment of abstraction as the student chooses, analyzes and determines what information is attending to get the correct answer of the problem, see Figure 2. The third exercise taken from Bebras named Spies focuses on evaluating the ability of generalization; because once that verifies the right solution for the initial problem; applied to a similar situation to solve the problem that has similar characteristics, see Figure 3. Two reagents are taken from the Computer Olympiad, the first named Beavers on the Run is chosen to evaluate the ability of algorithmic design because the student to resolve it shows your ability to understand the organization of instructions for solving a problem, in this case the indications for beavers cross holes, see Figure 4 . The second reagent named Puddle Jumping is chosen to determine the ability of evaluation, perform step by step instructions to complete the exercise and obtain the requested response, see Figure 5.

During the first days of September the test is applied to 65 new students. The following results for each of the reagents were obtained:

To exercise that evaluates decomposition $33.8 \%$ answers the correct answer. To exercise that evaluates abstraction $52.3 \%$ got the right answer. To exercise that evaluates generalization $36.9 \%$ answered correctly. To exercise that evaluates the algorithmic design $73.8 \%$ responded appropriately. To the question that assessment the ability of evaluation $67.7 \%$ selected the answer. Full results are in Figure 6.

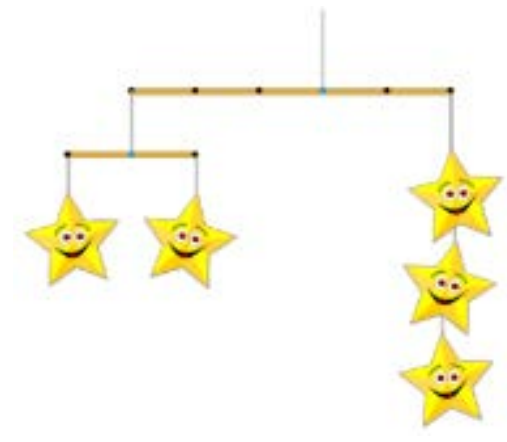

Figure 1. Description of Mobile with an expression: (-3 (-1 1) (1 1)) (2 3) 


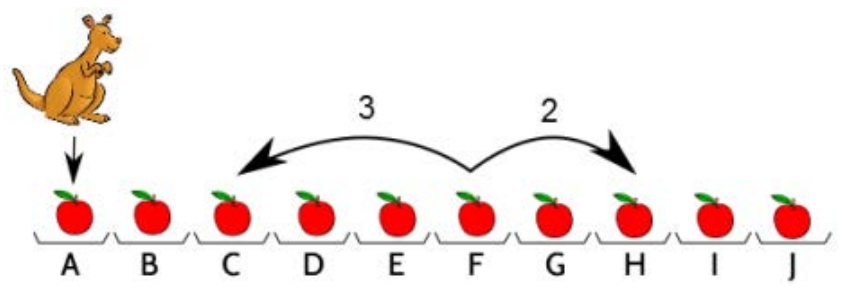

Figure 2. The task of picking apples

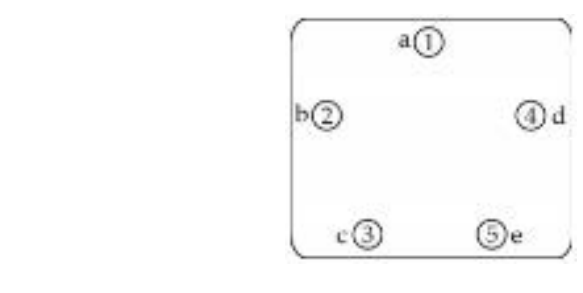

Figure 3. Five spies exchanging information

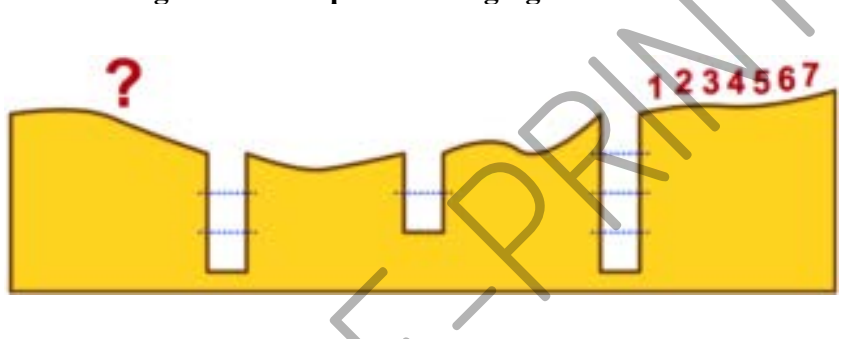

Figure 4. Seven beavers looking cross hole

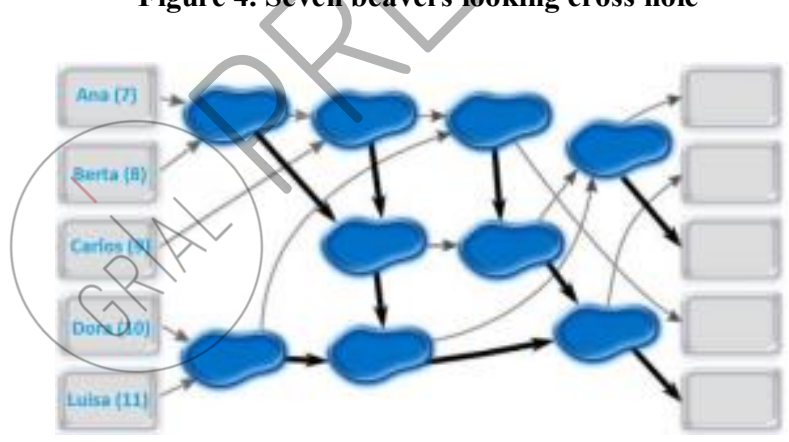

Figure 5. Puddle Jumping

$1 \mathrm{C}$ and 1D groups offer an inhomogeneous work, which corresponds to the individuality of students; the activities proposed to offer the student an initial learning environment based on reagents answered correctly, they are identified in 10 stages:

\section{Scenario 1. Five right answers}

The student has right to online material course and he can perform fifteen days after of start the quarter the evaluation of the thematic units through tests developed using the Moodle platform and deliver practical exercises created by the academy, if approving the results, the student accredits the course, otherwise a date for the review in person teacher-student exercises is determined, doubts are clarified and the student can choose, new practical exercises to evaluate or take the online course.

Scenario 2. Wrong exercise Beavers on the Run

The student must reinforce the algorithmic design with exercises through the Moodle platform, perform full course evaluations one month after the quarter started and determine whether he accredits the subject or choose to take it online. 


\section{Scenario 3. Wrong exercise Puddle Jumping}

Strengthen sequential, decision and repetition structures, coding specific exercises that solve a problem using the control structures. Scheduling attendance counseling for these issues and laboratory practice, make full course evaluations a month after the quarter started and determine to approve the subject or choose to take it online.

Scenario 4. Wrong exercises Beavers on the Run and Puddle Jumping

The student has right to use the online material course and he can practice activities to programs exercises of structured programming proposed by the academy, he can schedule three sessions of counseling with the teacher and he may ask the evaluation of online surveys and practical exercises a month started the quarter. If accredits their assessments, also the course, otherwise he can choose to take the course online or semi- distance.

Scenario 5. Wrong exercise Spies

Strengthen evaluation of arithmetic, logical and relational expressions considering the hierarchy of operators through coding exercises using calculations and conditional operations; make a month after the quarter started full course evaluations and determine whether he accredits or choose to take it online.

\section{Scenario 6. Wrong exercises Beavers on the Run, Puddle Jumping and Spies}

The student can work a semi- distance model, where the course material and activities will be released based on the specified time on the road course, requesting counseling sessions with the teacher of the course, make the practices and examinations at times marked by the academy.

\section{Scenario 7. Right exercise Kangaroo or Mobile}

The student has basic skills, but particularly necessary for learning programming, so he can choose for a semi- distance environment, but with an attention in person counseling regular in laboratory practices; perform departmental evaluations indicated by the academy and the student will perform practical exercises to develop the skills they need reinforcement, Generalization and Algorithmic design.

\section{Scenario 8 . Wrong on all reagents}

There is a possibility that student does not have skills to study the Career and the thematic unit three will be difficult to understand (control structures and algorithmic design), so it is recommended in student-teacher-principal meeting to assess the vocational profile. It is very sure that the classroom course is the best option for the student.

Scenario 9. Wrong exercises Mobile and Kangaroo

The student will work with a semi-distance model; he must select one day peer week for laboratory practice.

Scenario 10. Right exercises Beavers on the run and Puddle Jumping

The student can study online first two thematic units, after five weeks work with a semi-distance model.

Future work is to get more results of the proposed scenarios and the level learning of student when they graduate the first quarter.

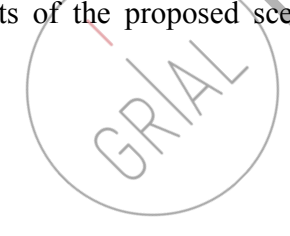




\section{Eleroidio}

¿Cuál de los anteriores móviles puede ser construido usando éstas instrucciones? $(-3(-14)(2(-11)(11)))(2(-16)(23))$

(os ripusutin)
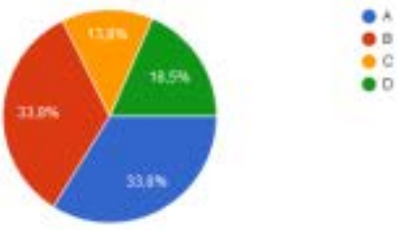

Eleroikio 2

Si Tomás recoge todas las 10 manzanas, ¿Cuál manzana recoge al final? A, B, C, D, E, F, G, H, I, OJ.

105 rempintino

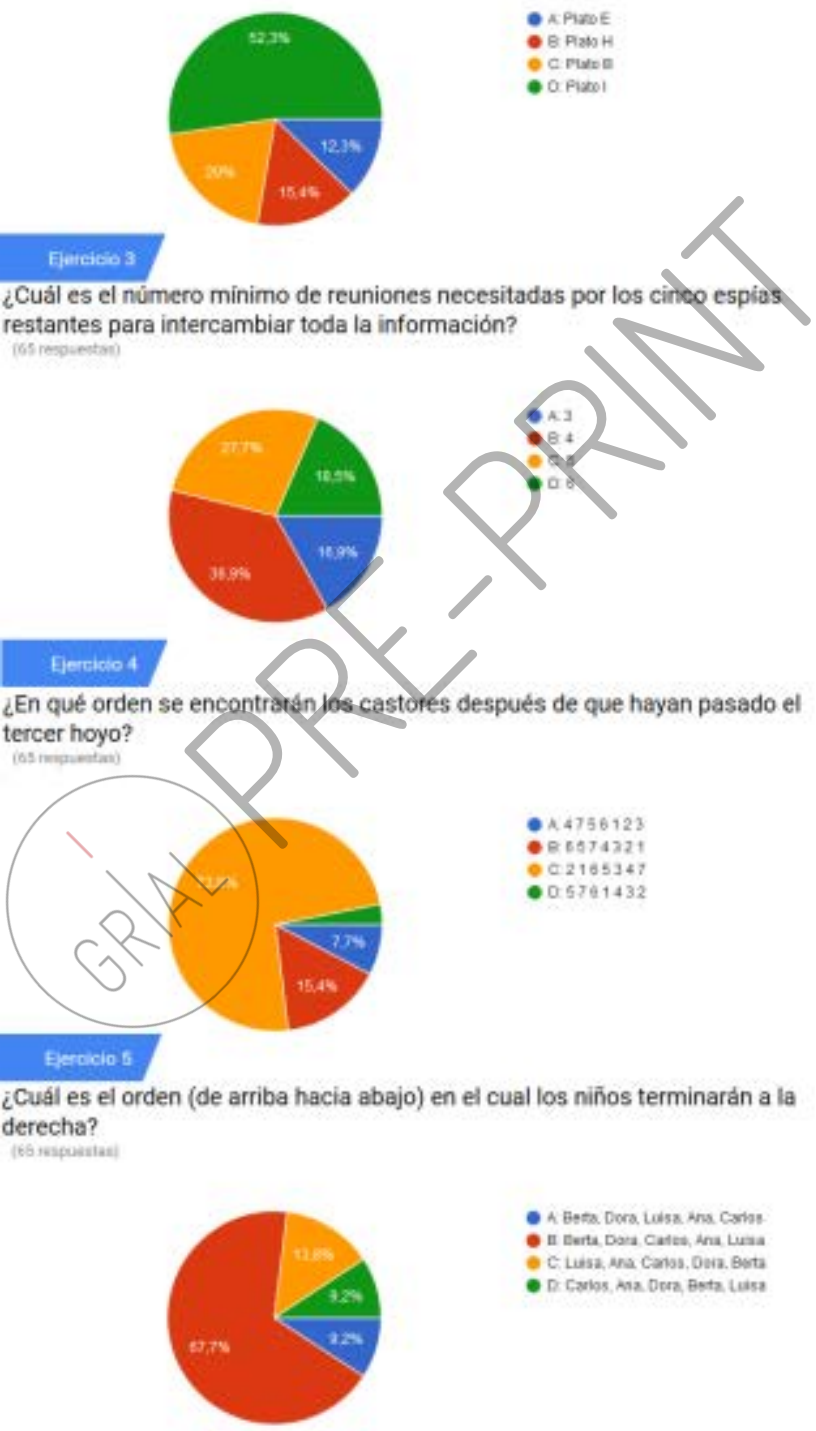

Figure 6. Full results $1 \mathrm{C}$ and $1 \mathrm{D}$

\section{DISSERTATION STATUS}

Guided by the calendar proposed in research plan, it is being met with the implementation of activities, in addition to being performing the tasks in respective month. Table 1 indicates in gray activities that are current and in black the activities implemented for the period 2015 2016; in the same way Table 2 indicates for the period 2016-2017. 
Table 1. Activities in cycle 2015-2016

\begin{tabular}{|c|c|c|c|c|c|c|c|c|c|c|c|}
\hline \multirow[t]{2}{*}{ Activity } & \multicolumn{3}{|l|}{2015} & \multicolumn{8}{|c|}{2016} \\
\hline & o 0 & $=$ & $\approx$ & क & of & 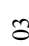 & t & ' & \& & s & $\stackrel{\infty}{\circ}$ \\
\hline \multicolumn{12}{|l|}{$\begin{array}{l}\text { Administrative } \\
\text { transactions }\end{array}$} \\
\hline \multicolumn{12}{|l|}{ Literature review } \\
\hline \multicolumn{12}{|l|}{$\begin{array}{l}\text { Appointment of } \\
\text { Director }\end{array}$} \\
\hline \multicolumn{12}{|l|}{$\begin{array}{l}\text { Elaboration of the } \\
\text { research plan }\end{array}$} \\
\hline \multicolumn{12}{|l|}{$\begin{array}{l}\text { Check and } \\
\text { approval of the } \\
\text { project. } \\
\text { Systematic review } \\
\text { of literature }\end{array}$} \\
\hline \multicolumn{12}{|l|}{$\begin{array}{lr}\begin{array}{l}\text { Preparation } \\
\text { articles }\end{array} & \text { of } \\
\text { publication } & \text { for } \\
& \end{array}$} \\
\hline $\begin{array}{lr}\text { Development } & \text { and } \\
\text { validation } & \text { of } \\
\text { instruments } & \end{array}$ & & & & & & & & & & & \\
\hline
\end{tabular}

Table 2. Activities in cycle 2016-2017

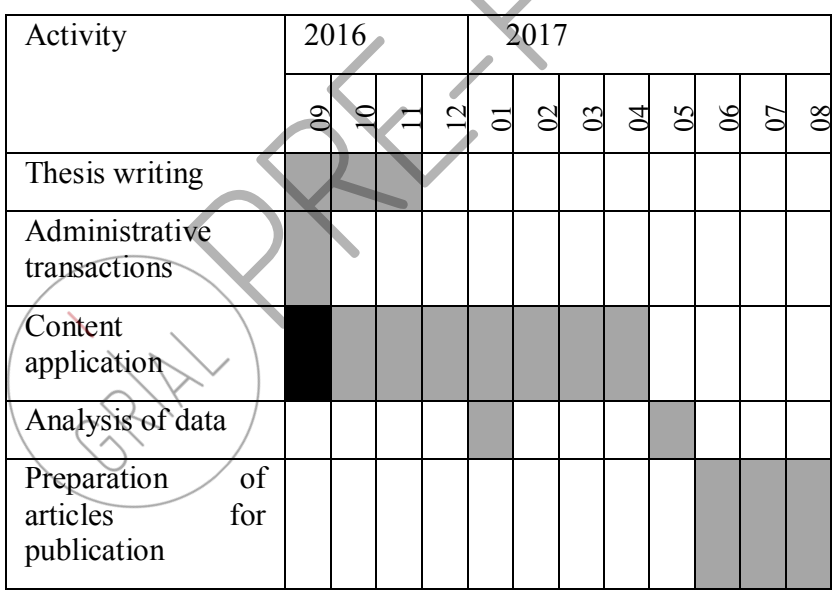

\section{CURRENT AND EXPECTED CONTRIBUTIONS}

Currently they are used seven of the ten proposed scenarios personalized learning for 65 students. The application of computational thinking test allowed the generation of the working groups; the important work of research is underway, information and observations that can be obtained may be used for future courses even outside the University.

\section{ACKNOWLEDGEMENTS}

This research work is made within University of Salamanca PhD Programme on Education in the Knowledge Society scope.

\section{REFERENCES}

[1] Olivares J. C., Jiménez J. A., Ortiz O., and Rodríguez N. 2015. Desarrollo de una aplicación para fortalecer el aprendizaje de los fundamentos de programación. Revista de ciencia e ingeniería del instituto tecnológico superior de Coatzacoalcos, 2.

[2] Wing, J. M. 2006. Computational Thinking. Communications of the ACM, 49(3), 33-35. DOI=http:// 10.1145/1118178.1118215

[3] Google for Education. 2016. Exploring Computational Thinking [Page web] https://www.google.com/edu/resources/programs/exploring-computational-thinking/ 
[4] Fidalgo A., Sein M. L., and García, F. J. 2015. Identifying Educational Innovation Characteristics. 3rd International Conference in Technological Ecosystems for Enhancing Multiculturality (TEEM 2015), Octubre, 2015, Porto, Portugal

[5] Wing, J. M. 2011. Research Notebook: Computational Thinking--What and Why? The Link. The magazine of the Carnegie Mellon University School of Computer Science.

[6] García, F. J. 2016. What Computational Thinking Is. Journal of Information Technology Research, 9(3).

[7] CSTA. 2011. K-12 Computer Science Standars. Retrieved from http://csta.acm.org/Curriculum/sub/CurrFiles/CSTA_K-12_CSS.pdf.

[8] TACCLE 3 Consortium. 2016. TACCLE 3: Coding Erasmus + Project website. Retrieved from http://www.taccle3.eu/

[9] García, F. J. 2016. Proyecto TACCLE3 - Coding. In F. J. García-Peñalvo \& J. A. Mendes (Eds.), XVIII Simposio Internacional de Informática Educativa, SIIE 2016 (pp. 187-189). Salamanca, España: Ediciones Universidad de Salamanca.

[10] García, F. J. 2016. Presentation of the TACCLE3 Coding European Project. Retrieved from http://repositorio.grial.eu/handle/grial/654

[11] European Schoolnet. 2015. Computing our future - Computer programming and coding, Priorities, school curricula and initiatives across Europe.

[12] James L., and George L. F. 2009. Thinking about computational thinking, Proceedings of the 40th ACM technical symposium on Computer science education, Chattanooga, TN, USA, pp. 260-264.

[13] Román, M., Pérez, J. C., and Jiménez, C. 2015. Test de Pensamiento Computacional: diseño y psicometría general Computational Thinking Test: design \& general psychometry, III Congreso Internacional sobre Aprendizaje, Innovación y Competitividad (CINAIC 2015), Octubre 14-16, 2015, Madrid, España

[14] Ferraro, P., Álvarez, L., and García, F. J. 2004. Adaptive Educational Hypermedia Proposal Based on Learning Styles and Quality Evaluation. In P. De Bra \& W. Nejdl (Eds.), Adaptive Hypermedia and Adaptive Web-Based Systems. 3rd International Conference, AH 2004, Proceedings (pp. 316-319). Berlin: Springer Verlag.

[15] Berlanga, A. J., and García, F. J. 2005. IMS LD reusable elements for adaptive learning designs. Journal of Interactive Media in Education, 11 .

[16] Berlanga, A. J., and García, F. J. 2005. Learning Technology Specifications: Semantic Objects for Adaptive Learning Environments. International Journal of Learning Technology, 1(4), 458-472. DOI= http://10.1504/IJLT.2005.007155

[17] Berlanga, A. J., and García, F. J. 2008. Learning Design in Adaptive Educational Hypermedia Systems. Journal of Universal Computer Science, 14(22), 3627-3647. DOI=http://10.3217/jucs-014-22-3627

[18] Lerís, D., and Sein, M. L. 2011. La personalización del aprendizaje: Un objetivo del paradigma educativo centrado en el aprendizaje. Arbor, 187(Extra_3), 123-134. DOI=http://10.3989/arbor.2011.Extra-3n3135

[19] García, F. J. 2016. Ecosistemas de Aprendizaje Adaptativos. Retrieved from http://repositorio.grial.eu/handle/grial/613 http://www.slideshare.net/grialusal/ecosistemas-de-aprendizaje-adaptativos

[20] Calderero J.F., Aguirre A. M., Castellanos A., Peris R.M., and Perochena P. 2014. Una nueva aproximación al concepto de educación personalizada y su relación con las TIC. Education in the Knowledge Society, 15(2), 131-151.

[21] Gao, P. 2014. Using Personalized Education to take the place of Standardized Education, Journal of Education and Training Studies, 2(2), 44-47.

[22] Tekin, C., Braun, J., and Van Der Schaar, M. 2015. ETutor: Online learning for personalized education. ICASSP, IEEE International Conference on Acoustics, Speech and Signal Processing - Proceedings, 2015-August, art. no. 7179032, pp. 5545-5549.

[23] Moodle. 2016. Moodle Statistics [Page web]. https://moodle.net/stats/

[24] García, F. J. 2015. Cómo entender el concepto de presencialidad en los procesos educativos en el siglo XXI. Education in the Knowledge Society (EKS), 16(2), 6-12. doi: http://dx.doi.org/10.14201/eks2015162612

[25] González, A. B., Rodríguez, M. J., Olmos, S., Borham, M., and García, F. J. 2013. Experimental evaluation of the impact of blearning methodologies on engineering students in Spain. Computers in Human Behavior, 29(2), 370-377. doi:10.1016/j.chb.2012.02.003

[26] Salinas, J., Darder, A., and De Benito, B. 2015. Las TIC en la enseñanza superior: e-learning, b-learning y m-learning. In J. Cabero \& J. Barroso (Eds.), Nuevos retos en tecnología educativa (pp. 153-174). Madrid, España: Síntesis

[27] Sein, M.L., Fidalgo, A., and García, F.J. 2015. Metodología de enseñanza inversa apoyada en b-learning y gestión del conocimiento, III Congreso Internacional sobre Aprendizaje, Innovación y Competitividad (CINAIC 2015), Octubre 14-16, 2015, Madrid, España

[28] Hernández R., Fernández C., and Baptista P. 2006. Metodología de la Investigación. (4ª Ed.). México: Mc. Graw Hill.

[29] Ramírez, M. S. 2012. Modelos y estrategias de enseñanza para ambientes innovadores. México: Editorial digital Tecnológico de Monterrey. 
[30] Selby, C.C. 2015. Relationships: computational thinking, pedagogy of programming, and Bloom's Taxonomy. In Proceedings of the Workshop in Primary and Secondary Computing Education (WiPSCE '15). ACM, New York, NY, USA, 80-87, DOI= http://dx.doi.org/10.1145/2818314.2818315.

[31] UK Bebras Computational Thinking Challenge, answers 2015. University of Oxford, available http://www.bebras.org

[32] Talent Search. 2015. Elite: Grade 12+, Institute of IT Professionals South Africa, available http://www.olympiad.org.za

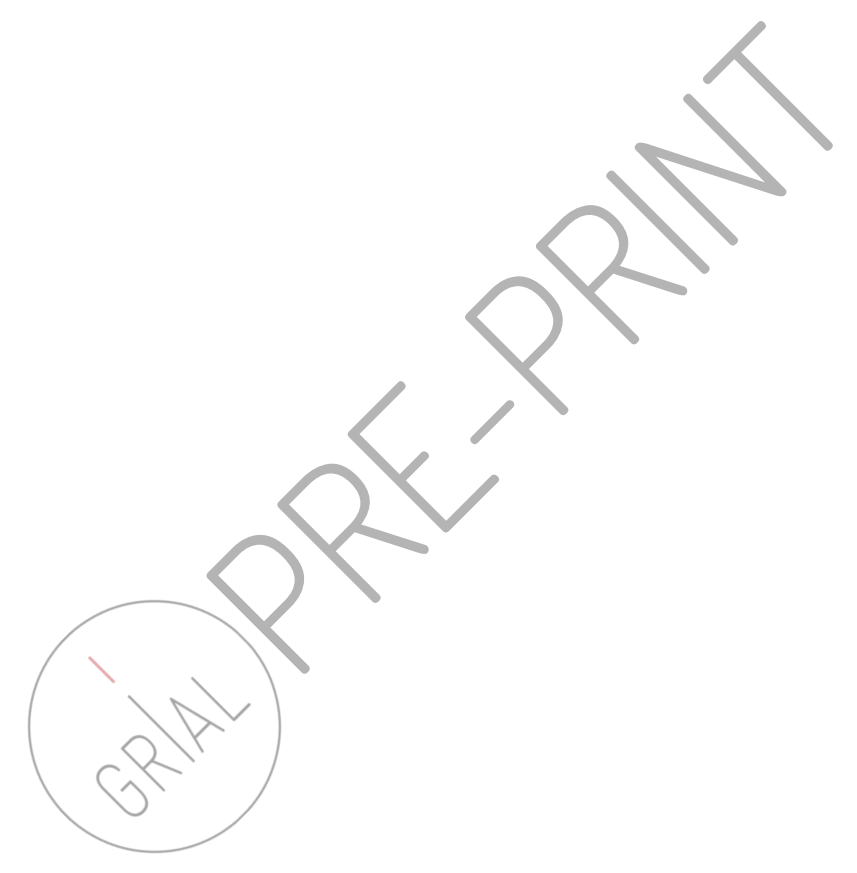

